\title{
Sobre un posible proceso de paz con el Ejército de Liberación Nacional (ELN)
}

\author{
Entrevista a Antonio Navarro Wolf \\ Senador de la República de Colombia.
}

\author{
Por Jacobo Cortez y Natalia Escobar \\ Estudiantes de Ciencia Política, Universidad Icesi.
}

Jacobo Cortez (JC): La primera pregunta es la siguiente: ¿Considera usted que a partir de los discursos políticos que da el ELN y su contradicción entre el hacer y el decir, pueden contribuir políticamente al país en un proceso de postconflicto?

Antonio Navarro Wolf (ANW): bueno el ELN no está todavía sentado en una mesa formal con el gobierno, $y$ todos los días nos dicen ¡Ya, la semana entrante, la otra semana! La impresión que todavía tengo es que por ahora el ELN no se va sentar con el gobierno en la mesa a hacer un acuerdo de paz; se están digamos resistiendo, esperando que se ter- mine el proceso con las FARC para en una etapa posterior ellos tratar de poner sus propias condiciones de cómo debe ser la mesa con ellos. Además, el ELN tiene como concepción que "la victoria no es ganar, sino no ser derrotados", para ellos es una gran victoria no haber sido derrotados en Arauquita, por ejemplo, en el gobierno de Uribe. Entonces, yo veo que el ELN por ahora no está digamos en la disposición de dar el paso de sentarse a negociar, entre otras cosas, porque consideran que quedarían obligados a aceptar lo que se negoció con las FARC, $\mathrm{y}$ ellos quieren tener su propia agenda. 
"Creo que el esfuerzo de conformar fuerzas alternativas a la política tradicional, es buscar cambiar el establecimiento político tradicional y su métodos ciertos: el clientelismo, la politiquería, la corrupción, la mermelada. Es distanciarse de aquellos que vienen gobernando con estos métodos de siempre, es presentar una alternativa real a todo eso"

JC: Actualmente, lo que se dicho es que cuando ha habido un intento por abordar al ELN, se dice que se ha hecho mediante proceso residuales de negociaciones en otros momentos, con la eventual firma del proceso de paz con las FARC ¿Cómo cree que se pueda afectar, o no, la posición que tiene el ELN y sentarse realmente a decir bueno "negociemos una paz"?

ANW: Ellos van a hacer todo lo necesario para aguantar, para seguir en esa especie de incertidumbre en que están y esperar a que termine el proceso con las FARC para intentar imponer unos métodos y unas condiciones dife- rentes en el futuro, o sea para el próximo gobierno. Lo que yo pienso, y ojalá esté equivocado, es que el ELN no va a negociar en este gobierno.

Natalia Escobar (NE): En caso de que se firme el proceso de paz, ¿hay suficiente dinero para el post-conflicto?

ANW: No hay un claro plan de posconflicto, lo primero es eso. Colombia no tiene mucho dinero ahora, y el dinero que tiene está bastante comprometido en otras cosas; pero viene una reforma tributaria que podría liberar, o producir unos recursos nuevos, que podían invertirse y que 
seguramente parte de ellos se van a invertir al pos-conflicto; pero lo que me preocupa es que no hay claro un plan para el post-conflicto. Sí, se le va a cumplir a las FARC lo que se acorde en la mesa y eso vale un dinero, pero eso no es suficiente. El posconflicto requiere lo que nosotros llamamos PIET (Presencia Integral del Estado en el Territorio) en esos territorios donde van a salir las guerrillas, y ese plan de PIET no lo tiene claro el gobierno, no lo tiene bien definido, no lo tiene evaluado. Es decir, tenemos más nosotros como grupo que lo que tiene el gobierno en este terreno. Le han dedicado mucho tiempo a la negociación y muy poquito a la preparación del día siguiente. Yo sí creo que eso va a pasar, va a llegar el día siguiente y vamos a tener que enfrentarnos a él con un gobierno que se verá forzado a ejectura un plan de acción que no se ha preparado. Este es otro ejemplo de esa mala constumbre colombiana de dejar todo para última hora.

NE: Y si el Estado no está preparado en estos momentos, ¿la sociedad colombiana sí estaría preparada?

ANW: La sociedad colombiana está preparada para el desarme de las FARC. Yo creo que sí. Pero el problema no es desarme de las FARC, el problema es que en esas regiones donde van a salir las FARC, van a llegar otros grupos armados; entonces, esa poblaciones van a estar sometidas a la presión de otros grupos armados. Además, seguramente un grupo armado van a ser las bandas criminales que en general tienen relaciones menos elaboradas con las población que las FARC; en este sentido, para esos colombianos no va cambiar mucho la situación, tal vez hasta empeore y eso es muy infortunado para el proceso.

JC: Se ha dicho mucho en otros países de cómo la izquierda tuvo un liderazgo en los procesos políticos ¿Cómo cree usted que, a partir del proceso de paz que se firme con las FARC y, eventualmente, también con el ELN, la izquierda quedará organizada? y ¿Quién podría liberar esa lucha política que permita concebir una izquierda como una fuerza política contundente?

ANW: La izquierda es una aura muy chiquita. Y si usted se mete es la jaula de la izquierdam se dará cuenta que va a ser chiquita para toda la vida. Aquí lo que hay que hacer es pensar en fuerzas alternativas que vayan más allá de la definición de izquierda. Si usted mira Améri- 
ca Latina, lo que se observa son fuerzas alternativas que se disputan el gobierno. Recientemente, se observa cierto retroceso, o mejor dicho, regreso a la tendencias tradicional de gobierno. Eso hay que imaginarselo como un péndulo va $\mathrm{y}$ viene, e independiente de lo que ocurra, por muy lejos que se vaya, va a volver otra vez. Lo gobiernos alternativos no son gobiernos estrictamente de izquierda ni de derecha, son gobiernos de fuerzas alternativas que forman coaliciones para agregar conjuntos sociales alternativos, pero cómo y quiénes van a liderar este proceso, es algo difícil predecir. Pero aquellos que están diciendo que nos estamos dirigiendo hacia una tendencia de izquierda, castrochavista, o como quieran llamarla, repito, están metiendose en un corral muy chiquito.

Creo que el esfuerzo de conformar fuerzas alternativas a la política tradicional, es buscar cambiar el establecimiento político tradicional y su métodos ciertos: el clientelismo, la politiquería, la corrupción, la mermelada. Es distanciarse de aquellos que vienen gobernando con estos métodos de siempre, es presentar una alternativa real a todo eso. En su momento, vimos un cambio en esa direccion con Antanas Mockus, o ya metidos de un modo más restringido también con Carlos Gaviria; pero es a ese tipo de alternativas a las que seguramente hay que apostarle porque lo que se viene, cuando cambie la agenda y se den cuenta de lo que hay que hacer, no solo con FARC sino con el modelo de desarrollo, con la manera de hacer política, con el calentamiento global, con la desigualdad, demanda nueva miradas. ¿Cuándo será que le va llegar la oportunidad a las fuerzas alternativas de gobernar a Colombia?, ¿Quiénes van a encabezar todo esto? son preguntas que hay que buscarle respuesta, pero estoy seguro de que se viene un cambio.

JC: Para ir finalizando, ¿Cómo percibe el rol de las juventudes de hoy frente al proceso de negociaciones y lo que se viene con el post-conflicto.

NE: Y comparándolo esto con los jóvenes de su generación.

ANW: Jóvenes que no quieran cambiar al mundo, es porque se ha envejecido antes de tiempo. El joven debe ser un agente cambio. Me parece que esto es algo fundamental, pero que se ha ido perdiendo. Nuestra juventud estaba mucho más politizada que la actual, tal vez estaba híper-politizada. Imagínese que yo pasé, digamos, de ingeniero de 
la Universidad del Valle, con beca de la fundación Rockefeller, a convertirme en guerrillero. Estaba híper-politizado, terminé dejando todo para meterme a la guerrilla como lo dictaban las lógicas de ese período. No obstante, sí creo que lo jóvenes tienen que seguir siendo una fuente de cambio, la fuerza fundamental para que la inercia que produce la edad, se modifique, y para que la historia se mueva a otros horizontes menos violentos y sangrientos. De manera que sí me gustaría que los jóvenes se interesarán más por los temas públicos, digamos que se politizarán un poco más. Creo que con una actitud de mayor participación en temas nacionales es suficiente que les permita ser agentes de cambio, como han sido siempre en todas las épocas de la historia.

JC: desde su perspectiva personal, por fuera de su investidura de senador, ¿Cómo ve usted a Colombia preparada para el día después de la firma?

ANW: Veo a Colombia poco preparado. Veo al país, en general, improvisando pero, al menos, intentando hacer lo que hay que hacer. Es que esta improvisado es mejor para la paz que continuar en el conflicto; es mejor firmar el acuerdo que continuar con el enfrentamiento armado. Por muy mal que nos vaya, va a mostrarnos un mejor escenario que el anterior. Con esto veo que se abre un cambio de agenda nacional, si no es en el 2018, lo será para el 2022, pero por fin, Colombia va a iniciar con una agenda, la del siglo XXI porque al fin y al cabo estamos cargando con una que se encuentra vigente a lo largo de toda la guerra desde mitad del siglo XX, que ya es un vejestorio, un dinosaurio que todavía sigue vivo y que es hora de dejerlo atrás para meternos en una nueva agenda política, social y económica.

NE y JC: ¡Muchísimas gracias! 